\title{
FUNDAMENTOS DA PSICOLOGIA: REFLEXÕES ${ }^{1}$
}

\author{
Lenita Gama Cambaúva*
}

\begin{abstract}
RESUMO. O presente texto é uma reflexão acerca de alguns fundamentos da Psicologia. Por ser um conceito fundamental para o conhecimento humano da relação sujeito e objeto, aborda-se, a partir de uma concepção histórico-social do homem, a constituição do conceito de subjetividade na história do pensamento. Expõe-se, de forma preliminar, como se deu o advento das Ciências Modernas e, com elas, a ênfase nas Ciências Naturais. Da mesma forma, focaliza-se também a crítica das Ciências Humanas às Ciências Naturais, e se observa como as primeiras formulações da Psicologia enquanto ciência vão se constituindo. O objetivo do texto é apontar a possibilidade de se chegar, através do estudo da dimensão epistemológica das psicologias, à dimensão ética das teorias e práticas, de forma que se possa avaliar quais psicologias dão a palavra ao homem.
\end{abstract}

Palavras-chave: História, Psicologia, subjetividade.

\section{PSYCHOLOGY FUNDAMENTS: CONSIDERATIONS}

ABSTRACT. The present study is a consideration about some of the Psychology fundaments. As it is a basic concept to human understanding of the subject and object relationship, it approaches, from the human historical-social view, the formation of the subjectivity concept in the thinking history. It is studied, in a preliminary way, how Modern Science was originated and the emphasis given to Natural Science. It also focuses on the criticism of Human Science in relation to Natural Science and how the first psychology formulations as a science are established. The objective of the present study is to point out the possibility of, through the studies of epistemological dimensions of psychology, reaching the ethic dimension of theories

1 O presente artigo é uma versão ampliada e reformulada para publicação da palestra proferida na Associação dos Diplomados da Escola Superior de Guerra - Curso de Especialização em Ciências Políticas, em julho de 1999.

* Mestre em Filosofia da Educação pela PUC/SP, professora Assistente do Departamento de Psicologia da Universidade Estadual de Maringá.

Endereço para correspondência: Departamento de Psicologia, Universidade Estadual de Maringá. Av. Colombo, 5790, 87020-900, Maringá, Paraná.

E-mail: lgcambauva@uem.br

\begin{tabular}{|l|l|l|l|l|l|}
\hline Psicologia em Estudo & DP/CCH/UEM & v. 5 & n. 2 & p. $77-89$ & 2000 \\
\hline
\end{tabular}


and practices, in order to evaluate which psychology provides the language to the human being.

Key words: History, Psychology, subjectivity.

Para discorrer sobre alguns dos fundamentos da Psicologia é necessário entendê-la como uma Ciência ao mesmo tempo antiga e jovem. Enquanto Ciência autônoma, é jovem, pois data da segunda metade do século XIX; entretanto, formulações psicológicas, como psique e fenômenos psíquicos (consciência, sensação, percepção, sonhos, memória) já preocupavam os filósofos da antigüidade.

O que busco entender, então, é como estas idéias psicológicas, já existentes na história do pensamento, são transformadas, a ponto de constituírem uma Ciência propriamente dita, cujo objeto específico são os fenômenos psíquicos e comportamentais. Para fazer este percurso, o do desenvolvimento da Psicologia enquanto ciência, ou ainda para descobrir seus fundamentos, vou abordar a história do pensamento humano.

De forma geral, existem duas grandes concepções de História, antagônicas quanto ao papel do homem no seu processo de desenvolvimento. Uma, denominada internalista ${ }^{2}$, pressupõe que as idéias científicas sejam produto de outras idéias e que a origem de um pensamento está no interior do sistema de idéias de uma época, não considerando, assim, fatores externos, como as condições sociais e econômicas. Segundo esta concepção, o homem atua por meio das idéias pelas idéias, criando individualmente formas de conhecimento. Ou seja, ela baseia-se no mito dos heróis da história do pensamento. É como se estes fossem eleitos ou privilegiados por alguma iluminação ou revelação de ordem sobrenatural, independentemente de toda condição material de vida. Instaura-se, assim, uma cisão entre o homem - produtor de idéias -, a produção de idéias e a ordem social.

Nos termos da outra concepção, denominada externalista ${ }^{3}$, a história do pensamento desenvolve-se totalmente condicionada aos interesses sociais, filosóficos e econômicos, segundo uma relação de causa e efeito, com traços mecanicista, fatalista e determinista. O homem

2 Penna(s/d) situa como representantes desta tendência Gaston Bachelard, Alexandre Koyré e Georges Canguilhem.

3 O mesmo autor situa Lucien Goldman e Imre Lakatos como representantes desta outra tendência. 
é aqui tratado como um ser resignado diante do mundo, que acredita que todos os acontecimentos independem de sua ação. Assim, não há o que fazer, não há perspectivas de mudanças, de transformações da ordem social vigente. Aqui também pode-se constatar a cisão entre produtor e produto, pois o homem não se reconhece como produtor, mas concebe as idéias como fruto ou conseqüência de interesses que estão fora dele.

Assim, se na concepção internalista o homem está acima de qualquer contextualização histórica, social e econômica, na concepção externalista o homem está aquém, submisso a estas condições. Sintetizando, numa é o herói que independe do mundo em que vive para produzir o conhecimento, e noutra é passivo e impotente para produzir alguma coisa que possa mudar a ordem estabelecida.

As duas concepções, na sua radicalidade, expressam uma oposição entre subjetividade (criação de idéias a partir de si mesmo) e objetividade (ocorrência de fatos considerados numa causalidade mecânica, que independe do homem).

O interessante, aqui, é apontar que a oposição ou cisão entre subjetividade e objetividade é um dos grandes dilemas da Psicologia, não só quando da sua constituição enquanto Ciência como também na atualidade. Isto parece sugerir não uma visão unitária da Psicologia, mas sim uma pluralidade, ou seja, psicologias com divergências quanto aos seus fundamentos teóricos e práticos. Só para exemplificar, temos entre as escolas de Psicologia Behaviorista e a Psicanálise ${ }^{4}$, cujos objetivos, objetos e métodos são diferentes, o que implica visões de mundo, de homem, e práticas psicológicas também diferentes.

Assim, evitando qualquer uma das cisões acima expostas, opto, neste texto, pela concepção histórico-social, que pode ser considerada como superação da concepção externalista, mecanicista, fatalista e determinista. De acordo com a concepção histórico-social, não se pressupõe o homem em total dependência e condicionamento em relação aos fatos externos. Este é considerado na sua condição humana de agente

4 Estou considerando a Psicanálise como uma teoria psicológica, apesar do fato de terse construído à margem das primeiras escolas psicológicas. Ainda, de acordo com Hall e Lindzey (1973), Freud nunca pensou em considerar a Psicanálise uma escola rival da Psicologia. Alguns historiadores da Psicologia, quando da exposição das escolas, incluem a Psicanálise, ora louvando-a como Psicologia, como Boring (citado por Schultz, 1975), ora defendendo que, apesar de ser polêmica devido a seu método, não pode ser ignorada pelas demais escolas de Psicologia, como Schultz (1975), Heidbreder (1933/1981) e Figueiredo (1995). 
prático-objetivo e agente reflexivo-subjetivo, ou seja, é um homem que, ao se relacionar com outros homens e com o mundo, transforma-se e transforma este mundo, a partir da atividade prática humana, o trabalho. Enquanto ser histórico-social, este homem não só faz a história, como vive nela e através dela. Portanto, se de um lado não é solipsista - crença cuja única realidade é o eu -, de outro não está fadado a se resignar diante dos fatos. Esta concepção está representada nas idéias sociológicas de Karl Marx e nas idéias psicológicas de Vigotsky, Leontiev, dentre outros.

De acordo com esta concepção, ao abordar a história do pensamento podemos identificar como os homens se apropriam da realidade e como vivem nela. A um só tempo, esta apropriação explicita a relação sujeito-objeto (como os homens conhecem a realidade) e explicita o conceito que fazem de si mesmos. A apropriação, enquanto processo de conhecimento, configura-se como uma mediação entre o homem e a natureza/realidade. A um só tempo engloba objetividade e subjetividade. A um só tempo impõe uma determinada relação com o exterior e uma determinada relação consigo mesmo, interior. E assim os homens vão constituindo um conceito sobre si mesmos e um (re)conhecimento daquilo que podem considerar como suas particularidades e diferenças com outros homens. Na perspectiva histórico-social não cabe a idéia de homem que se pensa independente da realidade que o rodeia, nem de um homem que se pensa só a partir desta realidade. Para a visão sócio-histórica, o homem vai se constituindo enquanto humano a partir da sua atividade prática, necessária para sua sobrevivência, que é o trabalho, e a partir das relações sociais que se constituem pelo e no trabalho. "Somente na história de vida prática dos homens cabe pensar a individualidade, que constitui o indivíduo, que o singulariza, que o distingue, mas ao mesmo tempo não se encerra nele”(Palangana,1998, p.07).

Entendo que a constituição da subjetividade é uma construção histórica. Se é histórica, pressupõe determinadas formas de o homem se apropriar do mundo e de si mesmo. Este ato de apropriação implica reconhecer a humanidade do homem na sua peculiaridade; entretanto, este reconhecimento só tem sentido se referenciado à totalidade da vida humana, se referenciado à vida material do homem.

$\mathrm{O}$ conceito que o homem tem de si mesmo passa por um longo processo de evolução e transformação, dado que quanto mais dependente é das forças produtivas da sociedade em que vive, menos possibilidade tem de se reconhecer enquanto indivíduo. 
Segundo Abib (1999, p.55),

Subjetividade refere-se à qualidade subjetiva-mental ou privada de algo, ou seja, refere-se a eventos, estados, processos e disposições mentais ou privadas que, por causa dessas qualidades, só podem ser de, ou pertencer a, ou estar em um sujeito.

Desta forma, parece que o processo de constituição do conceito da subjetividade na história do pensamento apresenta subsídios para se compreender alguns fundamentos da Psicologia. Enquanto o homem não tiver condições históricas para se tornar senhor de si, porque ora se sente ser da natureza, sem se opor a ela (como na sociedade grega), ora se sente superior a ela, mas se submete ao divino (como na sociedade medieval), não há necessidade de se ter uma área do conhecimento que se ocupe daquilo que o homem pensa, deseja, sente, ou de eventos, estados, processos mentais privados.

O projeto da Psicologia e seus fundamentos estão historicamente datados. É na história do pensamento humano, enquanto manifestação da vida material, que se tece a constituição do conceito de subjetividade: o homem ao longo de sua história vai constituindo sua humanidade, vai se humanizando e se apropriando dos fenômenos mentais como algo que lhe pertence.

Embora possamos frisar que os fenômenos psicológicos já eram tema na Antigüidade, posto que a preocupação do homem consigo mesmo é tão antiga quanto sua humanidade, não há necessidade histórica de a Psicologia emergir como ciência antes da Idade Moderna, dado que tanto na Sociedade Grega quanto na Medieval há sempre uma relação de dependência do homem com o mundo exterior que o limita e o impede de se apropriar inteiramente de si próprio, isto porque "nessas sociedades os indivíduos produzem a existência humana através de relações concretas, determinadas, pessoais, locais.”(Duarte, p.163).

A história do pensamento humano ocidental, sem dúvida, tem como marco inicial o aparecimento da filosofia grega, enquanto uma oposição ao pensamento mítico, característico das sociedades primitivas. É com a filosofia que o homem busca o conhecimento racional, lógico e sistemático da natureza, de si próprio e, portanto, de suas origens. O pensamento filosófico implica uma mudança de concepção de mundo que deve ser compreendida enquanto expressão de outra mudança - esta de 
ordem material-, que é a passagem do modo de produção baseado na coletividade para o modo de produção escravagista, baseado na propriedade privada. Pressupõe-se, então, que a filosofia, enquanto nova racionalidade do homem grego, é expressão das relações e das atividades reais, materiais que o homem mantém com o mundo.

As idéias psicológicas assinaladas no início do texto, a idéia de subjetividade e, portanto, de qualquer conceito de natureza psicológica, parecem ter-se firmado quando o homem, a partir da nova condição material de vida - o escravagismo - tem necessidade de uma nova racionalidade para compreender o mundo. Ou seja, o surgimento da concepção de subjetividade corresponde ao momento histórico em que o homem busca compreender seus comportamentos e seus estados psíquicos, posto que, com a nova forma de produção, não se confunde mais com a natureza, mas humaniza-se. O homem primitivo tem sua vida material marcada pelo imediatismo, pela produção coletiva sem excedentes, e, assim, não se diferencia da natureza/mundo. A sua forma de pensar é caracterizada pelo pensamento mítico, no qual a explicação, em forma de narrativa, da origem das coisas está fora do homem, está nos deuses ou nos astros. Não se dirige ao intelecto, mas ao imediato vivido, aos sentimentos, exigindo fé, confiança, adesão.

$\mathrm{Na}$ passagem da sociedade primitiva para a escravagista, o homem começa a diferenciar-se da natureza/mundo, busca não mais a revelação da origem das coisas e sim a compreensão do porquê das coisas. É aí, em meio ao advento da filosofia, que se tem também o advento das idéias psicológicas e, portanto, a constituição do conceito de subjetividade. O homem pergunta-se, questiona-se, cria os primeiros conceitos sobre alma, sonhos, memória. Ainda que reconheça sua humanidade, sente-se fazendo parte de algo muito maior, que é a natureza, o cosmo, a pólis. Esta conscientização não é exatamente “a do eu subjetivo, mas a consciência gradual das leis que determinam a essência humana”(Jaeger, 1986, p.10).

As indagações do homem quanto ao mundo e a si próprio põem, no centro das preocupações, o conhecimento e a verdade do conhecimento. A cada nova etapa da história da humanidade, a cada reorganização do modo de vida material, o homem buscou uma nova racionalidade para a compreensão do mundo e de si mesmo. Assim, na sociedade grega, o conhecimento considerado verdadeiro manifesta-se nos sentidos e no intelecto, porque a visão geral é a de que o homem é participante de toda a realidade: através do corpo, participa da natureza; 
através da alma, participa da inteligência divina. O mundo não é algo separado do homem, que deva ser assimilado pelo pensamento. O homem pertence ao mundo e o conhecimento se dá por meio de uma relação íntima e de comunhão entre o homem e o mundo. Sujeito e objeto do conhecimento mantêm identidade, ou pelo menos afinidade. ${ }^{5} \mathrm{~A}$ visão de mundo neste período é cosmocêntrica.

Num outro momento histórico, quando da superação do modo de produção escravagista para o modo de produção feudalista, há uma reorganização da vida material, que tem como base a produção coletiva, gerando relações sociais de dependência entre aquele que produz (servo) e aquele que se apropria da produção (senhor). Nessa sociedade a obediência ao superior é fundamental para a manutenção do modo de vida. O superior é tanto o senhor feudal quanto Deus. Desta forma, a noção de pecado capital, própria do cristianismo, propõe a separação do humano e do divino, evidenciando a fé como forma de o homem conhecer a verdade. Aqui, a visão de mundo é teocêntrica.

Estas condições do conhecimento e da verdade, características tanto da sociedade escravagista quanto feudalista, não questionam a capacidade humana de conhecer. É com a sociedade moderna, com a chamada revolução científica no século XVII, que esta questão aparece. O homem se volta para o que pode conhecer, e aí se evidencia o pensamento enquanto instância interior, e as coisas, enquanto instância exterior. Desta forma, a preocupação com o conhecimento e a verdade volta-se para a relação sujeito-objeto.

Nas chamadas sociedades pré-capitalistas, pela própria condição de vida material, o homem não consegue apropriar-se inteiramente de sua subjetividade. Nas relações sociais, no escravagismo, a propriedade privada também é o outro, o escravo, e o ideal de homem é o que serve à pólis. No feudalismo, o senhor feudal torna-se senhor coletivo, na medida em que, no seu feudo, a produção de bens necessários para a sobrevivência é auto-suficiente, havendo, quando muito, troca de bens, e leis que implicam deveres e obrigações mútuas. O conhecimento está submetido à Igreja. Estas duas formas de relações sociais não permitem ao homem apropriar-se de si mesmo. 
Este evento histórico - apropriação de si mesmo- só é possível com o capitalismo, cujo advento se deu através de transformações das relações sociais e de uma revolução no pensamento.

Podemos considerar como características gerais do capitalismo: produção abundante de mercadoria, aparecimento da classe trabalhadora livre e assalariada, propriedade privada, relação de troca mediada pelo dinheiro e não mais pelo valor de uso.

Se, de um lado, o capitalismo exige uma resposta para a produção de mercadorias (temos aí o advento da revolução industrial e a aliança entre conhecimento e produção), por outro exige também uma retomada do conhecimento humano, do homem enquanto linha de produção, enquanto força de trabalho, enquanto detentor do capital.

Nas chamadas sociedades pré-capitalistas existia uma concepção de mundo hierarquizado, estático, que apontava diferenças qualitativas entre o mundo terreno e o mundo dos astros: a concepção de subjetividade estava de acordo com estes ditames. Ou seja, o sujeito do conhecimento era ora participante das fontes explicativas da natureza (physis) ora submisso às fontes divinizadas (Deus), e nesse sentido o indivíduo, de forma geral, não precisava construir sua identidade. Havia uma pré-definição do indivíduo, que se dava através da cultura de eventos biográficos como nascimento, filiação, idade. Esta constituição da subjetividade está relacionada com a apropriação do conhecimento e, portanto, com a relação sujeito-objeto que o homem mantém, nesta apropriação. Como a concepção é de hierarquia, o homem não tem como se distanciar do objeto do conhecimento, pois este é pré-definido. Pode-se considerar que sua atitude enquanto sujeito do conhecimento é contemplativa.

Na sociedade capitalista, a relação sujeito/objeto do conhecimento transforma-se, na mesma medida em que se transforma a relação do indivíduo com o mundo. Agora, com a necessidade da Ciência de se aliar à produção, o ideal é o sujeito epistêmico pleno - pensante, dominador do conhecimento, regido pela razão e ação instrumental. Fica claro, então, que o homem deve construir o conhecimento, e ele mesmo deve validar este conhecimento, e, portanto, deve se afastar do objeto para conhecê-lo, ocorrendo uma ruptura na relação sujeito-objeto. O indivíduo deve, por si só, ser alguém, pois é considerado livre - livre das tradições, livre enquanto força de trabalho, livre para construir a própria identidade. Este é o contexto que se pode designar como sendo o do 
advento da subjetividade privatizada. ${ }^{6}$ Historicamente, há a superação da visão cosmocêntrica e teocêntrica de mundo, com a visão antropocêntrica. Neste sentido, com o capitalismo o homem não se remete mais ao exterior para se reconhecer: é sua eficiência, sua capacidade, sua produção que vão validar sua existência. De acordo com Figueiredo (1991b, p.20), “desde então, ser alguém pressupõe tornar-se alguém” (grifo do autor).

O ideal de sujeito epistêmico pleno e de indivíduo autônomo fracassa, já no próprio aparecimento.

Quando nasce o novo ideal de homem, nasce também a suspeita da sua capacidade de conhecimento, expressa nas metodologias do empirismo e do racionalismo. Busca-se, através de métodos e técnicas, a extirpação de tudo que lhe confere humanidade, porque os aspectos humanos, específicos do homem - vontade, sentimentos, etc... - não são passíveis de controle pela metodologia das Ciências Naturais.

As ciências modernas, cuja gestação se dá no século XVI, consolidando-se no século XVIII, pautam-se por uma concepção natural de homem; ou seja, o ramo de conhecimento que predomina nesse momento é o das Ciências Naturais, cujos estudos são pautados pelo método de observação, experimentação, mensuração, previsão e controle de seus objetos.

A consolidação das Ciências Naturais, e sua insistente visão naturalista e objetiva de homem, propicia a crítica a estes pressupostos, objetivando o resgate da humanidade do homem através do advento das Ciências Humanas. Estas querem recuperar a essência do homem, a sua especificidade enquanto humano, ou ainda, dar voz à vida e calar a razão, dar voz à experiência vivida imediata e calar a experimentação controlada.

É neste eixo - aparecimento e fracasso do sujeito e indivíduo autônomo; consolidação das Ciências Naturais e sua crítica, com o advento das Ciências Humanas- que se têm os fundamentos da Psicologia ou o que podemos chamar de constituição do espaço psicológico ou projeto de Psicologia. ${ }^{7}$

6 Figueiredo (1991a) reporta-se à experiência da subjetividade privatizada nos seguintes termos "esta experiência de sermos sujeitos capazes de decisões, sentimentos e emoções privadas só se desenvolve e se difunde amplamente numa sociedade com determinadas características”. (p.17).

cf. Figueiredo, 1991 b. 
A questão que precisa ser desenvolvida, então, é o porquê da constituição deste espaço ou deste projeto ocorrer nesse momento histórico e não em outro.

O advento da subjetividade privatizada está relacionado ao capitalismo, porque este impõe ao homem não só ser alguém independente de tradição, mas também produzir a partir da sua capacidade de se identificar com uma especialização no trabalho. No capitalismo, vende-se o produto visando lucro e, portanto, o poder de barganha é próprio de cada um, pois cada homem deve defender os próprios interesses. Ainda há o mercado de trabalho que propõe ao homem, na falta de capital, vender sua força de trabalho em troca de um salário que possibilite a compra de produtos necessários para sua sobrevivência.

Esta liberdade - autonomia leva o homem a perder uma série de apoios e meios de sustentação. De um lado, não dependendo mais da aldeia, família ou senhor, é um indivíduo desamparado, só. De outro, pode, em tese, fazer tudo o que quiser: é dono do seu destino. ${ }^{8}$

Num primeiro momento, os fundamentos da Psicologia estão calcados nas Ciências Naturais, pois estas, ao buscar o ideal de sujeito pensante, epistêmico, desconfia da natureza humana, ou seja, da subjetividade. Ora tende a submeter a subjetividade ao modelo das Ciências Naturais, ora busca a própria eliminação da subjetividade do sujeito quando da razão e ação do conhecimento - é daí que vem o conceito de neutralidade do pesquisador. Pois bem, adequar ou extirpar a subjetividade significa, em primeira mão, conhecê-la, daí a necessidade do projeto de Psicologia. Esta é a fase da pré-Psicologia científica, com o desenvolvimento de trabalhos na área da Fisiologia, entre os séculos XVIII e XIX (com o Associacionismo e estudos no campo da Psicofisiologia), que vão sedimentar e legitimar o advento da Psicologia como Ciência Experimental, no século XIX. Em síntese, há necessidade de se conhecer o psiquismo para controlá-lo. Eis aí a concepção de que o homem deve se adaptar ao seu meio. Aqui encontramos escolas da

8

Segundo Palangana (1998, p.21), com o advento do capitalismo “desestrutura-se a grande família organizada nos moldes feudais e emerge a família burguesa, cujos direitos e deveres de subsistência se restringem a pais e filhos. A riqueza deixa de ser herdada, como uma prerrogativa do nascimento, para advir do trabalho de cada um. A força para construir a própria riqueza, cada qual deve tirar de si mesmo. O princípio da sociedade emergente é o livre desenvolvimento das forças e capacidades individuais”. Pode-se também conferir esta idéia em Fiqueiredo (1991a). 
Psicologia calcadas no modelo das Ciências Naturais, com fundamentos na Matemática, na Biologia e na Fisiologia, sendo sua maior expressão, na atualidade, o Behaviorismo.

Num segundo momento, com o advendo das Ciências Humanas, buscam-se novos modelos metodológicos que descaracterizem a naturalização do homem e devolvam a ele sua especificidade humana. É com as Ciências Humanas que se implanta o método da hermenêutica e o do historicismo como forma de criticar o método explicativo das Ciências Naturais. Para as primeiras, a explicação dos fenômenos humanos baseada nas Ciências Naturais só serve como descrição destes fenômenos, além do que o método da experimentação pressupõe previsão e controle. Ora, as Ciências Humanas querem resgatar o que há de vivência, sentimento, valores, significado das ações humanas; portanto, o método deve ser o da interpretação - que confere significado e sentido aos fenômenos psíquicos. Aqui temos outra face da Psicologia pré-científica, com as psicologias espiritualistas, que buscam na consciência, enquanto vivência imediata ou duração existencial do ser humano, o testemunho de tudo o que lhe acontece. A repercussão desta forma de pensar está nas psicologias humanistas, na Psicanálise ${ }^{9}$, na fenomenologia e no existencialismo.

Assim, a Psicologia está fadada, desde seu projeto, a grandes contradições: se reconhece seu objeto, na sua especificidade - pode ser Psicologia, mas não é considerada Ciência, posto que o modelo científico do conhecimento está ainda com forte tendência de objetividade, pontuada pelas Ciências Naturais; se desconhece seu objeto, ou seja, se busca adequar a subjetividade ao cientificismo ou eliminá-la do processo do conhecimento, descaracteriza-se como Psicologia, podendo tornar-se disciplina de qualquer outra Ciência, preferencialmente da Biologia.

Em síntese, os fundamentos da Psicologia estão tanto na Filosofia, nas Ciências Naturais como nas Ciências Humanas, embora tenha se firmado como Ciência através das Ciências Naturais.

Segundo Figueiredo (1991b), o determinismo da Psicanálise freudiana é funcional, e não mecanicista. Há, nesta perspectiva, um sentido, uma função nas manifestações psíquicas e comportamentais. O interessante seria, e aqui não é o momento, investigar, nesta teoria, conceitos como instinto, desenvolvimento e dinâmica da personalidade e conflito, que ora permitem uma análise que pressupõe herança funcionalista, enquanto matriz cientificista, ora uma análise que pressupõe herança da hermenêutica, enquanto matriz romântica. 
Com esta breve reflexão, creio que se pode concluir que a contradição do projeto da Psicologia reflete, em muito, as divergências teórico-metodológicas das psicologias na atualidade, bem como a tentativa de vários autores da Psicologia de buscarem sua unificação. Por outro lado, creio que é somente por meio da reflexão sobre a História da Psicologia e suas implicações no plano das práticas sociais que se pode não só responder à necessidade ou não de sua unificação, como também entender a origem das divergências apontadas.

Se através da dimensão epistemológica é possível compreender como cada psicologia elabora o conceito de subjetividade, a dimensão ética nas práticas e discursos psicológicos está na compreensão de como as psicologias, a partir deste conceito, fazem o trânsito entre a objetividade, enquanto fenômeno que se explicita na relação dos homens com o mundo, e a subjetividade, enquanto fenômeno que não se explicita e que se caracteriza como o interditado ${ }^{10}$.

Sendo a constituição do conceito de subjetividade uma expressão histórica do pensamento humano, a reflexão sobre alguns fundamentos da Psicologia, a partir desta tese, pode esclarecer qual lugar cada psicologia ocupa no espaço sócio-cultural contemporâneo - aqui considerado o contexto onde se desenvolvem as relações sociais humanas constitutivas da subjetividade, como se articulam com as ideologias ${ }^{11}$ que propiciam a constituição da subjetividade na modernidade e como tratam a tão intrincada relação humana objetividade-subjetividade.

\section{REFERÊNCIAS BIBLIOGRÁFICAS}

Abbagnano, N. (1982). Dicionário de Filosofia (2 ${ }^{\mathrm{a}}$ ed. brasileira). São Paulo: Mestre Jou.

Abib, J.A. D. (1999). Empirismo radical e subjetividade. Psicologia: Teoria e Pesquisa. 1(15), 55-63.

Cambaúva, L.G \& Silva, L.C \& Ferreira, W. (1997). Da História da Psicologia à Psicologia Histórica. Psicologia em Estudo, 2, 113-124.

10 Segundo Figueiredo (1995, p.29), o meta fenomenal é o campo que vai além da experiência; assim, "cabe aos psicólogos, em primeiro lugar, ter os olhos para ver e (...) os ouvidos para escutar este interditado.”

11 Segundo Abbagnano (1982 p.506), o significado moderno do termo ideologia é (...) "uma doutrina, mais ou menos destituída de validade objetiva, porém mantida pelos interesses claros ou ocultos daqueles que deles se servem”. 
Cambaúva, L.G \& Silva, L.C \& Ferreira, W. (1998). Reflexões sobre o estudo da História da Psicologia. Estudos de Psicologia (Natal), 3 (2), 207-227.

Duarte, N. (1993). A individualidade para si: contribuição a uma teoria histórico-social da formação do indivíduo. Campinas: Autores Associados.

Figueiredo, L. C. M. (1991a). Psicologia: uma introdução: uma visão histórica da Psicologia como Ciência. São Paulo: Educ.

Figueiredo, L. C. M. (1991b). Matrizes do pensamento psicológico. Rio de Janeiro: Vozes.

Figueiredo, L. C. M. (1995). Revisitando as psicologias: da epistemologia à ética das práticas e discursos psicológicos. São Paulo: Educ; Petrópolis: Vozes.

Hall, C. S. \& Lindzey, G. (1973). Teorias da personalidade (1 ${ }^{\mathrm{a}}$ ed. brasileira). (L. Bretones, Trad.) São Paulo: Edusp.

Heidbreder, E. (1981). Psicologias do século XX (5 ed.). (L. S. Bland, Trad.) São Paulo: Mestre Jou. (Trabalho original publicado em 1933)

Jaeger, W. (1986). Padéia: a formação do homem grego. (1 $1^{a}$ ed. brasileira). (A.M. Parreira Trad.). São Paulo: Martins Fontes.

Palangana, I.C.(1998). Individualidade: afirmação e negação na sociedade capitalista. São Paulo: Plexus /Educ.

Penna, A.G. (s/d) História das idéias psicológicas. Rio de Janeiro: Zahar.

Schultz, D. (1975). História da Psicologia Moderna (2ª ed.). (A. Cabral Trad.) São Paulo: Cultrix.

Vernant, J.P. (1994). (Org.), O homem grego. (M. J. V. de Fiqueiredo Trad.) Lisboa: Editorial Presença. (Trabalho original publicado em 1984) 